\title{
Magnetic resonance imaging studies in bipolar disorder and schizophrenia: meta-analysis
}

\author{
D. Arnone, J. Cavanagh, D. Gerber, S. M. Lawrie, K. P. Ebmeier and A. M. McIntosh
}

\section{Background}

Several magnetic resonance imaging (MRI) studies have identified structural abnormalities in association with bipolar disorder. The literature is, however, heterogeneous and there is remaining uncertainty about which brain areas are pivotal to the pathogenesis of the condition.

\section{Aims}

To identify, appraise and summarise volumetric MRI studies of brain regions comparing bipolar disorder with an unrelated control group and individuals with schizophrenia.

\section{Method}

A systematic review and random-effects meta-analysis was carried out to identify key areas of structural abnormality in bipolar disorder and whether the pattern of affected areas separated bipolar disorder from schizophrenia. Significant heterogeneity was explored using meta-regression.

\section{Results}

Participants with bipolar disorder are characterised by whole brain and prefrontal lobe volume reductions, and also by increases in the volume of the globus pallidus and lateral ventricles. In comparison with schizophrenia, bipolar disorder is associated with smaller lateral ventricular volume and enlarged amygdala volume. Heterogeneity was widespread and could be partly explained by clinical variables and year of publication, but generally not by differences in image acquisition.

\section{Conclusions}

There appear to be robust changes in brain volume in bipolar disorder compared with healthy volunteers, although most changes do not seem to be diagnostically specific. Age and duration of illness appear to be key issues in determining the magnitude of observed effect sizes.

\section{Declaration of interest}

None.
Great interest has been focused on studying brain structure in individuals with bipolar disorder and schizophrenia. Several neuroimaging studies have been published, but there is still uncertainty about the key areas involved in the pathogenesis of these conditions. Meta-analysis as a technique is a tool to combine quantitative data from individual studies, increasing power to detect anatomical differences and investigate causes of heterogeneity. ${ }^{1,2}$

In schizophrenia and bipolar disorder meta-analyses of volumetric magnetic resonance imaging (MRI) studies have indicated that differences exist between affected individuals and healthy controls. In schizophrenia, meta-analyses have found evidence of reductions in the volumes of thalamus, hippocampus, anterior cingulate cortex ${ }^{3-5}$ and in the area of the corpus callosum. ${ }^{6,7}$ Wright et al broadly replicated the above findings but also showed reductions in cerebral volume with an enlarged ventricular system, particularly lateral ventricles. ${ }^{2}$ A more recent voxel-based meta-analysis also showed similar volumetric reductions in schizophrenia. ${ }^{8}$ In bipolar disorder, mild ventricular enlargement and the presence of white matter hyper-intensities ${ }^{9,10}$ are among the most consistently reported abnormalities. Kempton et al also reported larger lateral and third ventricles and smaller hippocampi in individuals with schizophrenia compared with those with bipolar disorder. Kempton et al considered a limited number of confounders and lithium prescribing was also associated with volumetric grey matter increases in bipolar disorder. ${ }^{10}$

In this meta-analysis we sought to update the work carried out by McDonald et al (2004) $)^{9}$ by focusing only on MRI studies. We extended our search strategy to: systematically include studies comparing people with bipolar disorder with those with schizophrenia apart from controls in an attempt to identify diagnosis-specific differences; and sought to quantify and explain between-study heterogeneity using meta-regression to examine the influence of key clinical and methodological variables.

\section{Method}

\section{Search strategy}

A systematic search was conducted from a range of electronic databases, including The Cochrane Library, EMBASE, PsycINFO, OVID and PubMED and complemented by a manual search with bibliographic cross-referencing. Key words used to identify the studies were: magnetic resonance imaging, MRI, bipolar disorder, mania, mood disorders and schizophrenia. Studies were included if they presented original data and were published by March 2008, compared individuals with schizophrenia, bipolar disorder and/or healthy controls, reported volumetric measures of brain areas according to the international system of units (SI units) as means and standard deviations. If standard deviations were missing from the published articles, these were conservatively estimated from the largest standard deviation of other studies that measured the same structure in the same volumetric units. Studies that included participants with unipolar depression were included provided participants with bipolar disorder made up more than $79 \%$ of the sample. Researchers were contacted if this information was not readily available. Studies were excluded if data were subsumed in more recent larger studies. Information systematically extracted from the studies included diagnosis according to diagnostic criteria, volumetric measurements and number of participants essential to calculate effect sizes, but also a number of potentially critical confounding variables. These included demographics (age, gender), illness variables (age at onset, duration of illness, presence of euthymia, medication, chronicity of the condition), year of publication, magnetic field strength of the scanner and slice 
thickness. Conference abstracts and letters were included only if there were no other publications from the same study that had been published in full as peer reviewed articles. Where a single study was published in several journal articles, the article reporting the largest group size for that volume of interest was used. When multiple publications were identified, disagreement was resolved by consensus between the authors. Studies were excluded when there was a comorbid diagnosis of intellectual disability, chromosomal or genetic disorder. Studies were included irrespective of slice thickness, although these factors were recorded as potential sources of heterogeneity. Studies were not included when the control group were genetically related to affected probands.

\section{Statistical analysis}

Statistical analysis was conducted using STATA 8.0 for Windows (Stata Corp, College Station, Texas) supplemented by Metan software (www.stata.com/stb/stb44/sbe24/metan.hlp; downloadable from the Centre for Statistics in Medicine, Oxford, UK). Standardised mean differences were calculated using Cohen's $d$ statistic.

Random effects analyses ${ }^{11}$ were used throughout to weight each study. The presence of heterogeneity was tested using the Q-test and its magnitude estimated using $I^{2}$ and can be interpreted as the proportion of variance in effect size due to heterogeneity. ${ }^{12}$ When the Q-test was significant, we used a Galbraith plot to identify those studies contributing the greatest amount to that heterogeneity, in order to investigate potential causes. Publication bias, which describes the tendency of small studies to report large effect sizes, was examined using the Egger's test. ${ }^{13}$ The significance level was set at $P<0.05$.

To further investigate causes for heterogeneity, meta-regression analyses were performed for the following variables: age at onset, duration of illness, presence of euthymia, chronicity, mean age, scanner strength, slice thickness, year of publication, and current medication, including mood stabilisers, antipsychotics and antidepressants. The STATA program 'metareg.ado' was used throughout and the REML (restricted maximum likelihood) method used to estimate the model parameters.

\section{Results}

\section{Systematic search}

Seventy-two reports ${ }^{14-85}$ from 180 studies identified met criteria for inclusion in the meta-analysis and are described in detail in online Table DS1. Sixty-five compared people with bipolar disorder with controls. Of these 65,18 articles included a further comparison group of individuals diagnosed with schizophrenia, ${ }^{15,16,36,46,49,52-54,56,58,59,65,68,75,80-82,85}$ one article added a third comparison group, of schizoaffective disorder ${ }^{83}$ and one compared with schizoaffective disorder but not with schizophrenia. ${ }^{45}$ Only two reports compared bipolar disorder with schizophrenia without the comparator of healthy controls. ${ }^{44,66}$

Thirty-six reports did not meet inclusion criteria mainly because authors used alternative or qualitative measurements of brain areas, reports were superseded by subsequent inclusive publications, volumes were not retrievable or there were fewer than three studies available for a given brain region. Years of publication ranged from 1990 to 2008. Studies were exclusively published in English. Studies used comparable diagnostic criteria and tested a total of 1823 participants with bipolar disorder, 670 with schizophrenia, 29 with schizoaffective disorder, 106 with unipolar depression (not included in the analysis) and 1940 healthy controls. This number includes duplicate publications investigating different brain regions. Same samples were considered only once in each individual analysis.

Studies generally considered individuals with recurrent episodes of illness who were treated with one or more mood stabilisers. Basic demographic characteristics were generally well reported but clinical details such as medication status, number of episodes, duration of illness, age at first presentation and illness subtype were not. Most studies included male and female participants but only a few offered separated analyses according to gender. There were 926 male participants with bipolar disorder, equivalent to $51 \%$ of the total sample. Age ranged from 10.6 to 58.8 years with a mean of 29.4 (s.d. $=11.8$ ).

\section{Bipolar disorder in comparison with healthy controls}

Comparisons of regional brain volumes between people with bipolar disorder and healthy controls are described in detail in online Table DS2. There was a small but significant reduction in whole brain volume in bipolar disorder $(n=661)$ compared with healthy controls $(n=723)$ with an estimated standardised effect size of $-0.15(95 \% \mathrm{CI}-0.27$ to -0.02$)$ and without significant heterogeneity $\left(I^{2}=0.23, P=0.15\right)$ or publication bias (Egger's $P=$ $0.9)$. Left and right lateral ventricles were significantly enlarged in bipolar disorder ( $n=157$, healthy controls $n=179$ ) with an effect size estimate of 0.27 (95\% CI $0.05-0.49)$ with no heterogeneity $\left(I^{2}=0, P=0.7\right)$ or publication bias (Egger's $\left.P=0.07\right)$. A larger number of studies $(n=11)$ measured lateral ventricles separately, suggesting a significant contribution of the left but not the right lateral ventricle, with no significant heterogeneity or publication bias. An analysis of five studies that measured the volume of the globus pallidus bilaterally ( $n=135$, healthy controls $n=106$ ) showed a significantly increased volume in participants with bipolar disorder (estimate $0.57,95 \%$ CI $0.03-1.11$ ) with a significant level of heterogeneity $\left(I^{2}=0.74, \quad P=0.004\right)$ and publication bias (Egger's $P=0.02$ ). This effect was not evident in the analysis of the three studies which measured the volume of the left and right globi pallidi separately (Table DS2).

\section{Bipolar disorder in comparison with schizophrenia}

Table DS2 shows that in comparison with schizophrenia, people with bipolar disorder showed an increased right amygdala volume ( $n=115$ v. $n=200$ ), effect size estimate $0.47,95 \%$ CI $0.21-0.73$, $I^{2}=0$, Egger's $P=0.59$. Lateral ventricles in bipolar disorder appeared bilaterally smaller than in schizophrenia $(n=126 \mathrm{v}$. $n=158$ ). The effect size estimate for the left lateral ventricle was: $-0.35,95 \%$ CI -0.59 to $-0.11, I^{2}=0.007$, Egger's $P=0.11$; for right lateral ventricle it was: $-0.26,95 \%$ CI -0.49 to $-0.02, I^{2}=0$; Egger's $P=0.06$. This effect was not present in the analysis of the three studies that measured the cumulative volume of left and right lateral ventricles (Table DS2).

\section{Heterogeneity and publication bias}

Heterogeneity and publication bias were not detected in structures that showed significant volumetric differences, except for whole brain grey matter and globus pallidus in the comparison of bipolar participants with healthy controls. Heterogeneity was, however, detected in a larger number of structures (as shown in Table DS2) and it is likely that methodological differences and clinical sample variation (including the effect of medication) are accountable for such an effect. With the limitation of selective reporting of relevant 

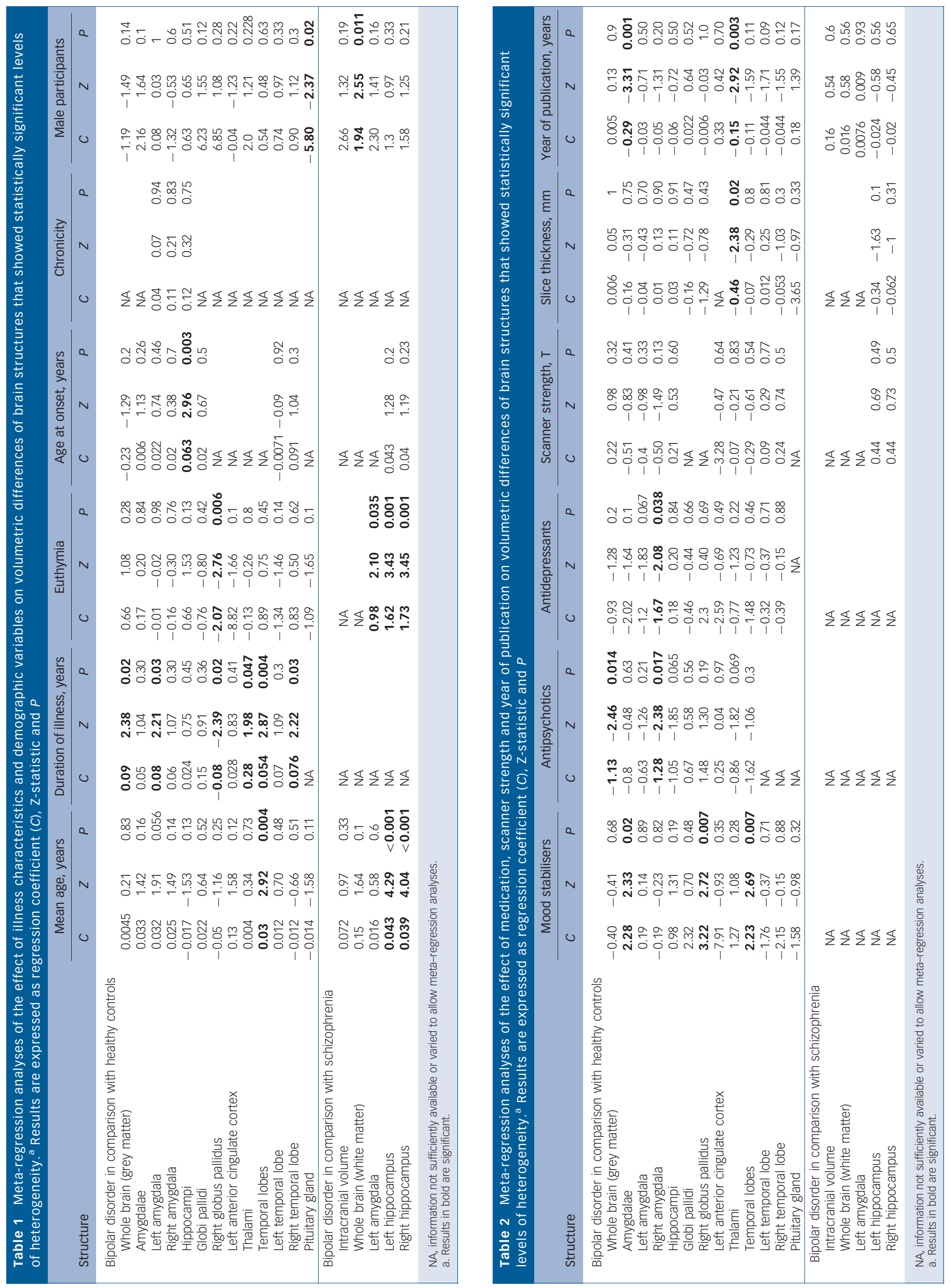
variables across the included studies we systematically investigated causes of heterogeneity in multiple meta-regression analyses. The results are displayed in Tables 1 and 2 and the main findings described below.

\section{Bipolar disorder in comparison with healthy controls}

In the comparison between people with bipolar disorder and healthy controls significant heterogeneity was found for several regions. The effect size for whole grey matter volume correlated with duration of illness $(C=0.09, Z=2.38, P=0.02)$ and use of antipsychotic medication $(C=-1.13, Z=-2.46, \quad P=0.014)$, suggesting larger bipolar $v$. control differences in people with longer durations of illness and larger reductions with use of antipsychotics, perhaps a proxy for a more severe illness. The differences in the right globus pallidus correlated with length of illness $(C=-0.08, Z=-2.39, P=0.02)$, percentage of participants with euthymia $(C=-2.07, Z=-2.76, P=0.006)$ and mood stabilisers $(C=3.22, Z=2.72, P=0.007)$, suggesting smaller differences with increasing illness duration and euthymia and increased differences with the use of mood stabilisers. In the amygdalae, volumetric differences tended to increase with the use of mood stabilisers $(C=2.28, Z=2.33, P=0.02)$ and to decrease with increasing year of publication $(C=-0.29$, $Z=-3.31, P=0.001)$. In the left amygdala, volumes increased with duration of illness $(C=0.08, Z=2.21, P=0.03)$. In the right amygdala, volumes decreased in relation to use of antipsychotic and antidepressant medication $(C=-1.28, Z=-2.38, P=0.017$ and $C=-1.67, Z=-2.08, P=0.038$ respectively). The hippocampi differences between participants with bipolar disorder and controls correlated positively with age at onset $(C=0.063$, $Z=2.96, P=0.003$ ), suggesting larger bipolar $v$. control hippocampal differences in individuals with a later age at onset. The effect size with respect to the thalami correlated negatively with year of publication $(C=-0.15, Z=-2.92, P=0.003)$ and slice thickness $(C=-0.46, \quad Z=-2.38, \quad P=0.02)$, and positively with duration of illness $(C=0.28, Z=1.98, P=0.047)$. These findings suggest that the thalami may have been smaller in individuals with bipolar disorder in more recently published studies and in studies where larger voxel sizes were used. However, the observed non-significant reductions in participants with bipolar disorder may be less evident in those with longer durations of illness. Pituitary volumes were negatively associated with percentage of male participants $(C=-5.80, Z=-2.37, P=0.02)$. Volumetric differences in the temporal lobes correlated positively with mean age $(C=0.03, Z=2.92, P=0.004)$, duration of illness $(C=0.054, Z=2.87, P=0.004)$ and use of mood stabilisers ( $C=2.23, Z=2.69, P=0.007)$. These results suggest smaller volumetric differences in this region in bipolar disorder with increasing age, duration of illness and the use of mood stabilisers. Duration of illness was positively associated with bipolar-control differences in right temporal lobe volume $(C=0.076, Z=2.22$, $P=0.03)$

\section{Bipolar disorder in comparison with schizophrenia}

In the bipolar disorder $v$. schizophrenia comparison, whole brain volume was positively associated with percentage of male participants $(C=1.94, Z=2.55, P=0.011)$. Left amygdala volume was positively associated with number of participants with euthymia ( $C=0.98, Z=2.10, P=0.035$ ). Volume differences in the left and right hippocampus were positively associated with age $(C=0.043, Z=4.29, P<0.001$ and $C=0.039, Z=4.04, P<0.001$ respectively) and number of participants with euthymia
$(C=1.62, Z=3.43, P=0.001$ and $C=1.73, Z=3.45, P=0.001$ respectively).

\section{Discussion}

Findings from this report suggest that individuals with bipolar disorder in comparison with healthy controls are characterised by significant whole brain and prefrontal lobe reductions and by enlargement of the lateral ventricles and globus pallidus. These findings did not separate bipolar disorder from schizophrenia however, although schizophrenia was characterised by a greater degree of ventricular enlargement and by amygdala volume reduction.

The finding of a global brain volume reduction reported in this meta-analysis is a relatively novel one and is in keeping with a mild but significant increase in the volume of the lateral ventricles and sulcal prominence in mood disorders as demonstrated by Elkis et al. ${ }^{86}$ The fact that two previous metaanalyses, by Hoge et $a l^{87}$ and McDonald et al, ${ }^{9}$ which included 7 and 11 studies respectively did not find such a reduction suggests the presence of a small effect which might require a larger pool of studies ( $n=25,661$ patients and 723 controls) to allow detection. Our finding is supported by an absence of publication bias and lack of significant heterogeneity. Interestingly, we found that people with schizophrenia are characterised by a greater ventricular enlargement compared with those with bipolar disorder. Wright et al reported decreased mean cerebral volume in participants with schizophrenia in comparison with controls and a concordant ventricular system enlargement particularly evident in the left lateral ventricle. ${ }^{2}$ The significance of an enlarged lateral ventricular system in the pathophysiology of these two conditions and the more pronounced effect in schizophrenia could be attributable to a similar disease process with a different intensity or two separate processes with a similar outcome. Elkis et al found a similar effect in their meta-analysis of 11 studies but extended inclusion criteria to more generic mood disorder rather than bipolar disorder and to the whole ventricular system. ${ }^{86}$

No volumetric changes were detected in the amygdala in bipolar disorder compared with controls and this structure was significantly larger than in individuals with schizophrenia. Although current evidence indicates that the amygdala may be implicated in the aetiology and pathogenesis of unipolar depression, this role is not entirely established in bipolar disorder. In unipolar depression evidence from both structural and functional MRI studies suggests a possible volumetric reduction in the amygdala ${ }^{88}$ mirrored functionally by a biased emotional response in the recognition of different emotional states, particularly fear. ${ }^{89}$ With reference to bipolar disorder, the literature reports both increased ${ }^{16,37,78}$ and decreased volumetric changes in the amygdala, almost exclusively in adolescents with bipolar disorder. ${ }^{21,30}$ Although this discrepancy can be explained as an abnormal development trajectory in bipolar disorder, ${ }^{90}$ it is also possible that other variables/and or confounders might play a role. Abnormal activation of the amygdala has been reported in several functional MRI (fMRI) studies of schizophrenia using fearful faces. ${ }^{91-93}$ Our findings extend previous reports that suggest a mechanistic role for the amygdala in schizophrenia, by suggesting that volumetric deficits may be disease specific. ${ }^{94}$

Consistent with our finding of globus pallidus enlargement, several strands of evidence suggest that the basal ganglia are implicated in the aetiology of mood disregulation in bipolar disorder. ${ }^{95}$ Caligiuri et al, by using a motor reaction time task, showed that individuals with euthymia or hypomania exhibited 
increased caudate activity bilaterally and in the left globus pallidus whereas an increase in severity of depression was associated with a decrease in activity in the external segment of the right globus pallidus. ${ }^{96}$ In an earlier study with a similar design, the same group found that either people with mania or depression exhibited abnormally elevated blood oxygen level-dependent (BOLD) responses in cortical and subcortical areas. Individuals with mania and bipolar disorder had significantly higher BOLD responses in the left globus pallidus and significantly lower BOLD responses in the right globus pallidus compared with people with depression and bipolar disorder. ${ }^{97}$ Malhi et al (2004) in an fMRI experiment also found that people with bipolar disorder in the depressed phase shown pictures designed to evoke affective change recruited prefrontal and anterior cingulate cortices and additional subcortical limbic systems when compared with healthy individuals, in particular in the amygdala, thalamus, hypothalamus and medial globus pallidus. Patients and comparison participants displayed differential sensitivity to affective change with negative and positive affect induction producing converse patterns of activation. ${ }^{98}$

The finding of increased volumes in the globus pallidus is in keeping with several reports suggesting that antipsychotic drugs affect this structure, although this result was not confirmed in the left and right analysis of the structure, and the presence of publication bias and statistically significant unexplained heterogeneity limits the validity of results. Whether these changes are related to alterations in gamma-aminobutyric acid (GABA)/ dopamine neurotransmission or possibly the result of artefacts in the presence of ventricular enlargement will require further investigation.

In agreement with Kempton et als meta-analysis, ${ }^{10}$ in the bipolar disorder $v$. healthy controls comparison we found evidence of lateral ventricular enlargement in the absence of heterogeneity or publication bias. We also found evidence of whole brain and prefrontal lobe volume reductions, and globus pallidus volumetric increase. Similarly, in comparison with schizophrenia, bipolar disorder was associated with smaller lateral ventricular volume and enlarged amygdala volume. Our analysis did not confirm volumetric differences affecting the third ventricle or the hippocampi. Extensive meta-regression analyses confirmed the effect of mood stabilisers and other pharmacological compounds such as antipsychotics and antidepressants on morphometric differences. Finally several clinical and demographic variables exercise an effect on brain volumes. It is likely that the ability of meta-regression analyses to detect small differences is relatively limited. This observation, together with a different methodology can explain discrepancies in findings, although this meta-analysis largely confirms Kempton et al's findings. ${ }^{10}$

Some of the analyses reveal modest effect sizes. Whether these are clinically significant or scientifically important is, however, difficult to judge, as a very small change in the volume of a particular structure may have significant effects on behaviour. There is evidence of significant heterogeneity in several analyses. We predicted this would be the case and used random effects analyses that take heterogeneity into account when calculating all summary effect sizes. The effect of heterogeneity is to reduce the precision of the summary effect sizes and in general this reduces the significance of any findings. We have gone to considerable lengths to investigate this heterogeneity using meta-regression that we think has provided some much needed clarification for the considerable inconsistency in the published literature. Although this meta-analysis is limited by an inconsistency in the published literature, heterogeneity can provide important aetiological and methodological insights that can guide future research. We found several effect size associations with a number of both methodological and clinical variables (e.g. course/phase of bipolar disorder, medication status and treatment modalities) that should be borne in mind when designing future studies.

Another further potential limitation is the lack of studies that included a longitudinal perspective, such that it is difficult to exclude the possibility that the observed brain changes occur as a consequence of illness or its treatment. More neuroimaging studies with a longitudinal perspective could help clarify the natural evolution of brain abnormalities. Moorhead et al for instance found that people with bipolar disorder tend to lose hippocampal, fusiform and cerebellar grey matter at an accelerated rate compared with healthy controls and that tissue loss is associated with deterioration in cognitive function and illness course. ${ }^{99}$ Further understanding could also emerge from clear reporting of clinical variables such as duration of illness, age at onset and number of previous episodes. Finally, the selective reporting and publication of positive results is a further potential limitation to all meta-analyses. Although this limitation cannot be definitively excluded, we found evidence of publication bias only in a very limited number of structures.

In summary, we found that bipolar disorder is associated with global and prefrontal volumetric brain reductions, enlarged lateral ventricles and an enlarged globus pallidus. Compared with individuals with schizophrenia, people with bipolar disorder presented with a reduced right amygdala volume and smaller lateral ventricles.

\section{Arnone, DM, MRCPsych, Neuroscience and Psychiatry Unit, University of Manchester, Manchester and University Department of Psychiatry, Oxford; \\ J. Cavanagh, MD, FRCPsych, Division of Community Based Sciences, Faculty of \\ Medicine, University of Glasgow, Glasgow; D. Gerber, MRCPsych, Gartnavel Royal Hospital, Glasgow; S. M. Lawrie, MD, FRCPsych, Division of Psychiatry, University of Edinburgh, Royal Edinburgh Hospital, Edinburgh; K. P. Ebmeier, MD, Division of Psychiatry, University of Edinburgh, Royal Edinburgh Hospital, Edinburgh and University Department of Psychiatry, Oxford; A. M. McIntosh, MD, MRCPsych, Division of Psychiatry, University of Edinburgh, Royal Edinburgh Hospital, Edinburgh, UK}

Correspondence: Danilo Arnone, Neuroscience and Psychiatry Unit, University of Manchester, G810 Stopford Building, Oxford Road, Manchester M13 9PT, UK. Email: danilo.arnone@manchester.ac.uk

First received 28 Sep 2008, final revision 2 Jan 2009, accepted 4 Mar 2009

\section{Funding}

D.A. is currently supported by the UK Medical Research Council. A.M.M. is currently supported by the Health Foundation.

\section{Acknowledgements}

D.A. would like to thank Drs Pariante and MacMaster for supplementing their work with unpublished data to complete this meta-analysis.

\section{References}

1 Thompson SG, Smith TC, Sharp SJ. Investigating underlying risk as a source of heterogeneity in meta-analysis. Stat Med 1997; 16: 2741-58.

2 Wright IC, Rabe-Hesketh S, Woodruff PW, David AS, Murray RM, Bullmore ET. Meta-analysis of regional brain volumes in schizophrenia. Am J Psychiatry 2000; 157: 16-25.

3 Nelson MD, Saykin AJ, Flashman LA, Riordan HJ. Hippocampal volume reduction in schizophrenia as assessed by magnetic resonance imaging: a meta-analytic study. Arch Gen Psychiatry 1998; 55: 433-40.

4 Konick LC, Friedman L. Meta-analysis of thalamic size in schizophrenia. Biol Psychiatr 2001; 49: 28-38. 
5 Baiano M, David A, Versace A, Churchill R, Balestrieri M, Brambilla P. Anterior cingulate volumes in schizophrenia: a systematic review and a meta-analysis of MRI studies. Schizophr Res 2007; 93: 1-12.

6 Woodruff PW, McManus IC, David AS. Meta-analysis of corpus callosum in schizophrenia. J Neurol Neurosurg Psychiatry 1995; 58: 457-61.

7 Arnone D, Mcintosh AM, Tan GMY, Ebmeier KP. Meta-analysis of magnetic resonance imaging studies of the corpus callosum in schizophrenia. Schizophr Res 2008; 101: 124-32

8 Ellison-Wright I, Glahn DC, Laird AR, Thelen SM, Bullmore E. The anatomy of first-episode and chronic schizophrenia: an anatomical likelihood estimation meta-analysis. Am J Psychiatry 2008; 165: 1015-23.

9 McDonald C, Zanelli J, Rabe-Hesketh S, Ellison-Wright I, Sham P, Kalidindi $\mathrm{S}$, et al. Meta-analysis of magnetic resonance imaging brain morphometry studies in bipolar disorder. Biol Psychiatry 2004; 56: 411-7.

10 Kempton MJ, Geddes JR, Ettinger U, Williams SC, Grasby PM. Meta-analysis, database, and meta-regression of 98 structural imaging studies in bipolar disorder. Arch Gen Psychiatry 2008; 65: 1017-32.

11 DerSimonian R, Laird N. Meta-analysis in clinical trials. Control Clin Trials 1986; 7: $177-88$

12 Higgins JP, Thompson SG, Deeks JJ, Altman DG. Measuring inconsistency in meta-analyses. BMJ 2003; 327: 557-60.

13 Egger M, Davey Smith G, Schneider M, Minder C. Bias in meta-analysis detected by a simple, graphical test. BMJ 1997; 315: 629-34.

14 Ahn MS, Breeze JL, Makris N, Kennedy DN, Hodge SM, Herbert MR, et al Anatomic brain magnetic resonance imaging of the basal ganglia in pediatric bipolar disorder. J Affect Disord 2007; 104: 147-54.

15 Altshuler LL, Bartzokis G, Grieder T, Curran J, Mintz J. Amygdala enlargemen in bipolar disorder and hippocampal reduction in schizophrenia: an MRI study demonstrating neuroanatomic specificity. Arch Gen Psychiatry 1998; 55: 663-4.

16 Altshuler LL, Bartzokis G, Grieder T, Curran J, Jimenez T, Leight K, et al. An MRI study of temporal lobe structures in men with bipolar disorder or schizophrenia. Biol Psychiatry 2000; 48: 147-62.

17 Atmaca M, Ozdemir H, Cetinkaya S, Parmaksiz S, Belli H, Poyraz AK, et al. Cingulate gyrus volumetry in drug free bipolar patients and patients treated with valproate or valproate and quetiapine. J Psychiatr Res 2007; 41: 821-7.

18 Aylward EH, Roberts-Twillie JV, Barta PE, Kumar AJ, Harris GJ, Geer M, et al. Basal ganglia volumes and white matter hyperintensities in patients with bipolar disorder. Am J Psychiatry 1994; 151: 687-93.

19 Beyer JL, Kuchibhatla M, Payne M, Moo-Young M, Cassidy F, MacFall J, et al. Caudate volume measurement in older adults with bipolar disorder. Intern Geriatr Psychiatry 2004; 19: 109-14.

20 Beyer JL, Kuchibhatla M, Payne ME, Moo-Young M, Cassidy F, Macfall J, et al. Hippocampal volume measurement in older adults with bipolar disorder. Am J Geriatr Psychiatry 2004; 12: 613-20.

21 Blumberg HP, Kaufman J, Martin A, Whiteman R, Zhang JH, Gore JC, et al. Amygdala and hippocampal volumes in adolescents and adults with bipola disorder. Arch Gen Psychiatry 2003; 60: 1201-8.

22 Botteron KN, Vannier MW, Geller B, Todd RD, Lee BC. Preliminary study of magnetic resonance imaging characteristics in 8- to 16-year-olds with mania J Am Acad Child Adolesc Psychiatry 1995; 34: 742-9.

23 Brambilla P, Harenski K, Nicoletti MA, Mallinger AG, Frank E, Kupfer DJ, et al. Anatomical MRI study of basal ganglia in bipolar disorder patients. Psychiatry Res 2001; 106: 65-80.

24 Brambilla $\mathrm{P}$, Harenski $\mathrm{K}$, Nicoletti M, Mallinger AG, Frank E, Kupfer DJ, et al. MRI study of posterior fossa structures and brain ventricles in bipolar patients. J Psychiatr Res 2001; 35: 313-22.

25 Brambilla $P$, Harenski K, Nicoletti M, Mallinger AG, Frank E, Kupfer DJ, et al. Differential effects of age on brain gray matter in bipolar patients and healthy individuals. Neuropsychobiology 2001; 43: 242-7.

26 Brambilla P, Nicoletti MA, Harenski K, Sassi RB, Mallinger AG, Frank E, et al. Anatomical MRI study of subgenual prefrontal cortex in bipolar and unipolar subjects. Neuropsychopharmacology 2002; 27: 792-9.

27 Brambilla P, Harenski K, Nicoletti M, Sassi RB, Mallinger AG, Frank E, et al. MRI investigation of temporal lobe structures in bipolar patients. J Psychiat Res 2003; 37: 287-95.

28 Caetano SC, Sassi R, Brambilla P, Harenski K, Nicoletti M, Mallinger AG, et al. MRI study of thalamic volumes in bipolar and unipolar patients and healthy individuals. Psychiatry Res 2001; 108: 161-8.

29 Chang K, Barnea-Goraly N, Karchemskiy A, Simeonova DI, Barnes P, Ketter T, et al. Cortical magnetic resonance imaging findings in familial pediatric bipolar disorder. Biol Psychiatry 2005; 58: 197-203.
30 Chang K, Karchemskiy A, Barnea-Goraly N, Garrett A, Simeonova DI Reiss A. Reduced amygdalar gray matter volume in familial pediatric bipolar disorder. J Am Acad Child Adolesc Psychiatry 2005; 44: $565-73$

31 Chen BK, Sassi R, Axelson D, Hatch JP, Sanches M, Nicoletti M, et al. Cross-sectional study of abnormal amygdala development in adolescents and young adults with bipolar disorder. Biol Psychiatry 2004; 56: 399-405.

32 Chen $\mathrm{HH}$, Nicoletti $\mathrm{M}$, Sanches $\mathrm{M}$, Hatch JP, Sassi RB, Axelson D, et al. Normal pituitary volumes in children and adolescents with bipolar disorder: a magnetic resonance imaging study. Depress Anxiety 2004; 20: 182-6.

33 Chen $\mathrm{HH}$, Nicoletti MA, Hatch JP, Sassi RB, Axelson D, Brambilla P, et al. Abnormal left superior temporal gyrus volumes in children and adolescents with bipolar disorder: a magnetic resonance imaging study. Neurosci Lett 2004; 363: 65-8.

34 Chiu S, Widjaja F, Bates ME, Voelbel GT, Pandina G, Marble J, et al. Anterior cingulate volume in pediatric bipolar disorder and autism. J Affect Disord 2008; 105: 93-9.

35 Cousins D, Moore PB, Harrison L, Ferrier IN, Young AH, Lloyd AJ. Third ventricle width and pituitary volumes in euthymic bipolar subjects J Psychopharmacology 2007; 21 (suppl): A14.

36 Dasari M, Friedman L, Jesberger J, Stuve TA, Findling RL, Swales TP, et al. A magnetic resonance imaging study of thalamic area in adolescent patients with either schizophrenia or bipolar disorder as compared to healthy controls. Psychiatry Res 1999; 91: 155-62.

37 Davis KA, Kwon A, Cardenas VA, Deicken RF. Decreased cortical gray and cerebral white matter in male patients with familial bipolar I disorder. J Affect Disord 2004; 82: 475-85.

38 DelBello MP, Strakowski SM, Zimmerman ME, Hawkins JM, Sax KW. MRI analysis of the cerebellum in bipolar disorder: a pilot study. Neuropsychopharmacology 1999; 21: 63-8.

39 DelBello MP, Zimmerman ME, Mills NP, Getz GE, Strakowski SM. Magnetic resonance imaging analysis of amygdala and other subcortica brain regions in adolescents with bipolar disorder. Bipolar Disord 2004; 6: $43-52$.

40 Dupont RM, Jernigan TL, Heindel W, Butters N, Shafer K, Wilson T, et al. Magnetic resonance imaging and mood disorders. Localization of white matter and other subcortical abnormalities. Arch Gen Psychiatry 1995; 52 747-55.

41 El-Badri SM, Cousins DA, Parker S, Ashton HC, McAllister VL, Ferrier IN, et al. Magnetic resonance imaging abnormalities in young euthymic patients with bipolar affective disorder. Br J Psychiatry 2006; 189: 81-2.

42 Frazier JA, Chiu S, Breeze JL, Makris N, Lange N, Kennedy DN, et al. Structural brain magnetic resonance imaging of limbic and thalamic volumes in pediatric bipolar disorder. Am J Psychiatry 2005; 162: 1256-65.

43 Frazier JA, Breeze JL, Makris N, Giuliano AS, Herbert MR, Seidman L, et al. Cortical gray matter differences identified by structural magnetic resonance imaging in pediatric bipolar disorder. Bipolar Disord 2005; 7: 555-69.

44 Frazier JA, Hodge SM, Breeze JL, Giuliano AJ, Terry JE, Moore CM, et al. Diagnostic and sex effects on limbic volumes in early-onset bipolar disorder and schizophrenia. Schizophr Bull 2008; 34: 37-46.

45 Getz GE, DelBello MP, Fleck DE, Zimmerman ME, Schwiers ML, Strakowski SM. Neuroanatomic characterization of schizoaffective disorder using MRI: a pilot study. Schizophr Res 2002; 55: 55-9.

46 Harvey I PR, Ron MA, Baker G, Murray RM. Volumetric MRI measurements in bipolars compared with schizophrenics and healthy controls. Psychol Med 1994; 24: 689-99.

47 Hauser P, Matochik J, Altshuler LL, Denicoff KD, Conrad A, Li X, et al. MRI-based measurements of temporal lobe and ventricular structures in patients with bipolar I and bipolar II disorders. J Affect Disord 2000; 60: 25-32.

48 Haznedar MM, Roversi F, Pallanti S, Baldini-Rossi N, Schnur DB, Licalzi EM, et al. Fronto-thalamo-striatal gray and white matter volumes and anisotropy of their connections in bipolar spectrum illnesses. Biol Psychiatry 2005; 57 733-42.

49 Hirayasu Y, McCarley RW, Salisbury DF, Tanaka S, Kwon JS, Frumin M, et al. Planum temporale and Heschl gyrus volume reduction in schizophrenia: a magnetic resonance imaging study of first-episode patients. Arch Gen Psychiatry 2000; 57: 692-9.

50 Hwang J, Lyoo IK, Dager SR, Friedman SD, Oh JS, Lee JY, et al. Basal ganglia shape alterations in bipolar disorder. Am J Psychiatry 2006: 163: $276-85$. 
51 Javadapour A, Malhi GS, Ivanovski B, Chen X, Wen W, Sachdev P. Increased anterior cingulate cortex volume in bipolar I disorder. Aust $N Z$ Journal Psychiatry 2007; 41: 910-6.

52 Kasai K, Shenton ME, Salisbury DF, Hirayasu Y, Lee CU, Ciszewski AA, et al. Progressive decrease of left superior temporal gyrus gray matter volume in patients with first episode schizophrenia. Am J Psychiatry 2003; 160: $156-64$.

53 Kasai K, Shenton ME, Salisbury DF, Onitsuka T, Toner SK, Yurgelun-Todd D, et al. Differences and similarities in insular and temporal pole MRI gray matter volume abnormalities in first-episode schizophrenia and affective psychosis. Arch Gen Psychiatry 2003; 60: 1069-77.

54 Kasai K, Shenton ME, Salisbury DF, Hirayasu Y, Onitsuka T, Spencer MH, et al. Progressive decrease of left Heschl gyrus and planum temporale gray matter volume in first-episode schizophrenia: a longitudinal magnetic resonance imaging study. Arch Gen Psychiatry 2003; 60: 766-75.

55 Kaur S, Sassi RB, Axelson D, Nicoletti M, Brambilla P, Monkul ES, et al. Cingulate cortex anatomical abnormalities in children and adolescents with bipolar disorder. Am J Psychiatry 2005; 162: 1637-43.

56 Lim KO, Rosenbloom MJ, Faustman WO, Sullivan EV, Pfefferbaum A. Cortical gray matter deficit in patients with bipolar disorder. Schizophr Res 1999; 40: 219-27.

57 Lopez-Larson MP, DelBello MP, Zimmerman ME, Schwiers ML, Strakowski, SM. Regional prefrontal gray and white matter abnormalities in bipolar disorder. Biol Psychiatry 2002; 52: 93-100.

58 McDonald C, Marshall N, Sham PC, Bullmore ET, Schulze K, Chapple B, et al. Regional brain morphometry in patients with schizophrenia or bipolar disorder and their unaffected relatives. Am J Psychiatry 2006; 163: 478-87.

59 McIntosh AM, Forrester A, Lawrie SM, Byrne M, Harper A, Kestelman JN, et al. A factor model of the functional psychoses and the relationship of factors to clinical variables and brain morphology. Psychol Med 2001; 31 159-71

60 Mills NP, Delbello MP, Adler CM, Strakowski SM. MRI analysis of cerebellar vermal abnormalities in bipolar disorder. Am J Psychiatry 2005; 162: 1530-2.

61 MacMaster FP, Leslie R, Rosenberg DR, Kusumakar V. Pituitary gland volume in adolescent and young adult bipolar and unipolar depression. Bipolar Disord 2008; 10: 101-4.

62 Monkul ES, Nicoletti MA, Spence D, Sassi RB, Axelson D, Brambilla P, et al. MRI study of thalamus volumes in juvenile patients with bipolar disorder. Depress Anxiety 2006; 23: 347-52.

63 Noga JT, Vladar K, Torrey EF. A volumetric magnetic resonance imaging study of monozygotic twins discordant for bipolar disorder. Psychiatry Res 2001; 106: 25-34.

64 Pariante CM, Dazzan P, Danese A, Morgan KD, Brudaglio F, Morgan C, et al. Increased pituitary volume in antipsychotic-free and antipsychotic-treated patients of the AEsop first-onset psychosis study. Neuropsychopharmacology 2005; 30: 1923-31.

65 Pearlson GD, Barta PE, Powers RE, Menon RR, Richards SS, Aylward EH, et al. Ziskind-Somerfeld Research Award 1996. Medial and superior temporal gyra volumes and cerebral asymmetry in schizophrenia versus bipolar disorder. Biol Psychiatry 1997; 41: 1-14.

66 Rossi A, Stratta P, Di Michele V, Gallucci M, Splendiani A, de Cataldo S, et al. Temporal lobe structure by magnetic resonance in bipolar affective disorders and schizophrenia. J Affect Disord 1991; 21: 19-22.

67 Rosso IM, Killgore WD, Cintron CM, Gruber SA, Tohen M, Yurgelun-Todd DA Reduced amygdala volumes in first-episode bipolar disorder and correlation with cerebral white matter. Biol Psychiatry 2007; 61: 743-9.

68 Roy PD, Zipursky RB, Saint-Cyr JA, Bury A, Langevin R, Seeman MV. Temporal horn enlargement is present in schizophrenia and bipolar disorder. Biol Psychiatry 1998; 44: 418-22.

69 Sanches M, Sassi RB, Axelson D, Nicoletti M, Brambilla P, Hatch JP, et al. Subgenual prefrontal cortex of child and adolescent bipolar patients: a morphometric magnetic resonance imaging study. Psychiatry Res 2005; 138 43-9.

70 Sanches M, Roberts RL, Sassi RB, Axelson D, Nicoletti M, Brambilla $\mathrm{P}$, et al. Developmental abnormalities in striatum in young bipolar patients: a preliminary study. Bipolar Disord 2005; 7: 153-8.

71 Sassi RB, Nicoletti M, Brambilla P, Harenski K, Mallinger AG, Frank E, et al. Decreased pituitary volume in patients with bipolar disorder. Biol Psychiatry 2001; 50: 271-80.

72 Sassi RB, Nicoletti M, Brambilla $\mathrm{P}$, Mallinger AG, Frank E, Kupfer DJ, et al. Increased gray matter volume in lithium-treated bipolar disorder patients. Neurosci Lett 2002; 329: 243-5.
73 Sassi RB, Brambilla P, Hatch JP, Nicoletti MA, Mallinger AG, Frank E, et al. Reduced left anterior cingulate volumes in untreated bipolar patients. Biol Psychiatry 2004; 56: 467-75.

74 Sax KW, Strakowski SM, Zimmerman ME, DelBello MP, Keck PE, Jr, Hawkins $J M$. Frontosubcortical neuroanatomy and the continuous performance test in mania. Am J Psychiatry 1999; 156: 139-41.

75 Schlaepfer TE, Harris GJ, Tien AY, Peng LW, Lee S, Federman EB, et al. Decreased regional cortical gray matter volume in schizophrenia. Am J Psychiatry 1994; 151: 842-8.

76 Sharma V, Menon R, Carr TJ, Densmore M, Mazmanian D, Williamson PC. An MRI study of subgenual prefrontal cortex in patients with familial and non-familial bipolar I disorder. J Affect Disord 2003; 77: 167-71.

77 Strakowski SM, Wilson DR, Tohen M, Woods BT, Douglass AW, Stoll AL. Structural brain abnormalities in first-episode mania. Biol Psychiatry 1993; 33: 602-9.

78 Strakowski SM, DelBello MP, Sax KW, Zimmerman ME, Shear PK, Hawkins $\mathrm{JM}$, et al. Brain magnetic resonance imaging of structural abnormalities in bipolar disorder. Arch Gen Psychiatry 1999; 56: 254-60.

79 Strakowski SM, DelBello MP, Zimmerman ME, Getz GE, Mills NP, Ret J, et al. Ventricular and periventricular structural volumes in first- versus multiple-episode bipolar disorder. Am J Psychiatry 2002; 159: 1841-7.

80 Strasser HC, Lilyestrom J, Ashby ER, Honeycutt NA, Schretlen DJ, Pulver $A E$, et al. Hippocampal and ventricular volumes in psychotic and nonpsychotic bipolar patients compared with schizophrenia patients and community control subjects: a pilot study. Biol Psychiatry 2005; 57: 633-9.

81 Swayze VW 2nd, Andreasen NC, Alliger RJ, Ehrhardt JC, Yuh WT. Structural brain abnormalities in bipolar affective disorder. Ventricular enlargement and focal signal hyperintensities. Arch Gen Psychiatry 1990; 47: 1054-9.

82 Swayze VW 2nd, Andreasen NC, Alliger RJ, Yuh WT, Ehrhardt JC. Subcortical and temporal structures in affective disorder and schizophrenia: a magnetic resonance imaging study. Biol Psychiatry 1992; 31: 221-40.

83 Velakoulis D, Wood SJ, Wong MT, McGorry PD, Yung A, Phillips L, et al. Hippocampal and amygdala volumes according to psychosis stage and diagnosis: a magnetic resonance imaging study of chronic schizophrenia, first-episode psychosis, and ultra-high-risk individuals. Arch Gen Psychiatry 2006; 63: 139-49.

84 Yucel K, Taylor VH, McKinnon MC, Macdonald K, Alda M, Young LT, et al. Bilateral hippocampal volume increase in patients with bipolar disorder and short-term lithium treatment. Neuropsychopharmacology 2008; 33: 361-7.

85 Zipursky RB SM, Bury A, Langevin R, Wortzman G, Katz R. Deficits in gray matter volume are present in schizophrenia but not bipolar disorder. Schizophr Res 1997; 26: 85-92.

86 Elkis H, Friedman L, Wise A, Meltzer HY. Meta-analyses of studies of ventricular enlargement and cortical sulcal prominence in mood disorders. Comparisons with controls or patients with schizophrenia. Arch Gen Psychiatry 1995; 52: 735-46.

87 Hoge EA, Friedman L, Schulz SC. Meta-analysis of brain size in bipolar disorder. Schizophr Res 1999; 37: 177-81.

88 Phillips ML, Drevets WC, Rauch SL, Lane R. Neurobiology of emotion perception II: Implications for major psychiatric disorders. Biol Psychiatry 2003; 54: 515-28.

89 LaBar KS, Gatenby JC, Gore JC, LeDoux JE, Phelps EA. Human amygdala activation during conditioned fear acquisition and extinction: a mixed-trial fMRI study. Neuron 1998; 20: 937-45

90 McEwen BS, Milner TA. Hippocampal formation: shedding light on the influence of sex and stress on the brain. Brain Res Rev. 2007; 55: 343-55.

91 Fahim C, Stip E, Mancini-Marie A, Mensour B, Boulay LG, Leroux JM et al. Brain activity during emotionally negative pictures in schizophrenia with and without flat affect: an FMRI Study. Psychiatry Res 2005; 140: 1-15.

92 Schneider F, Weiss U, Kessler C, Salloum JB, Posse S, Grodd W, et al. Differential amygdala activation in schizophrenia during sadness. Schizophr Res 1998; 34: 133-42.

93 Baas D, Aleman A, Vink M, Ramsey NF, de Haan EH, Kahn RS. Evidence of altered cortical and amygdala activation during social decision-making in schizophrenia. Neuroimage 2008; 40: 719-27.

94 Soares JC, Mann JJ. The functional neuroanatomy of mood disorders. J Psychiatr Res 1997; 31: 393-432.

95 Goldman AL, Pezawas L, Mattay VS, Fischl B, Verchinski BA, Zoltick B, et al. Heritability of brain morphology related to schizophrenia: a large-scale automated magnetic resonance imaging segmentation study. Biol Psychiatry 2008; 63: 475-83. 
96 Caligiuri MP, Brown GG, Meloy MJ, Eberson S, Niculescu AB, Lohr JB. Striatopallidal regulation of affect in bipolar disorder. J Affect Disord 2006; 91: 235-42.

97 Caligiuri MP, Brown GG, Meloy MJ, Eberson SC, Kindermann SS, Frank LR, et al. An fMRI study of affective state and medication on cortical and subcortical brain regions during motor performance in bipolar disorder Psychiatry Res 2003; 123: 171-82.
98 Malhi GS, Lagopoulos J, Ward PB, Kumari V, Mitchell PB, Parker GB, et al. Cognitive generation of affect in bipolar depression: an fMRI study. Eur J Neurosci 2004; 19: 741-54.

99 Moorhead TW, McKirdy J, Sussmann JE, Hall J, Lawrie SM, Johnstone EC, et al. Progressive gray matter loss in patients with bipolar disorder. Biol Psychiatry 2007; 62: 894-900.

\section{Why I chose psychiatry}

\section{Ian Rowbotham}

\section{Part one - In the Beginning}

'Most of you will become GPs', said the smooth lecturer, himself a consultant, a word which once meant Great Beast of the Swamplands. But gene dilution diminished its potency; thus it begat consultant nurse, consultant physiotherapist, consultant (car sales) and consultant hospital cardiac specialist (drug rep.), consultant accountant (turf) and subspecies too numerous and complicated to spell.

With DNA weakened, having neither Awayday awareness certificate nor distance learning MSc to protect against the approaching cataclysm, they were hit hardest. General practitioner (prosapiamedicus), no longer 'slacker' and 'also ran', walked over the Earth, terrorising governments. These intelligent, well-adjusted creatures mated early, saw their progeny grow up and drank in the bounteous new dawn.

The old, lumbering predators grew scarce, further handicapped by the twin eruptions of 'Emmemsi' and 'Emtasse' in 2007. Their descendants ran amok panicking, stricken by shortages, blinded by fallout, even charging round on 7-hour ward rounds at night and weekends, as their dominion shrivelled and the more nimble-footed opt-out doctors (Cotidieopus) joined the ascendancy.

\section{Part two - Apres le Déluge (moi)}

A mature student of mature years, I had watched in wonderment from the first rumblings of Tomorrow's Doctors. I had seen two great eras: Surgery and Medicine. Next came the Paediatrics and the Age of Endoctrinement, then, as a meteor paints the sky with its single daub of brilliance, Psychiatry. Seven weeks of revelation followed. I could understand its language, follow the puzzling, yet attractive logic and uncertainty; there were also many people. The full tide of human existence was not, as Samuel Johnson put it, at Charing cross but right here in the vortex of my medical school career. These were not bags of symptoms to be diagnosed, treated and pressure-hosed through the rotating door of MAU, but human lives; part of the joyful, tragic, brutal, desperate web of experience.

Our course organiser, and head of year, made sure Psychiatry formed a good chunk of exams (wake up!). We visited a secure hospital, attended interactive lectures and clinics, saw child, liaison, eating disorders and drug and alcohol psychiatry culminating with a forensic flourish in a mock murder trial.

\section{Part three - flying solo}

FY1 colleagues asked, 'What did you do before medicine?' (I made musical noises on a piece of wood) and, 'Are you going to do General Practice? (I'll do anything, make the tea). But was I a GP? It was an obvious choice, but Psychiatry's small flame persisted, illuminating the hallways and passages of my mind.

Psychiatry at FY2 (getting serious) was another positive experience. Then came Orthopaedics (deeply enjoyed but never intended as a career). I set 4 months to decide, but the Damascene moment came during the second week, when I was asked to review a frail elderly man, debilitated with Parkinson's disease, who had been given a new hip. He had become agitated 3 days post op and had 'punched' the physiotherapist (how?) and 'throttled' a nurse (serious cricoid trauma was, fortunately, avoided). What I subsequently found may have decided my choice of career. Clearly frightened, he believed patients were being systematically murdered (they were being discharged), addressed me as Dr Death (justifiable given my spirited drilling technique) and claimed police were outside to interview me about the killings. He was plainly terrified and, after further investigation, plainly psychotic. Owing to his severe Parkinson's, I prescribed Quetiapine $25 \mathrm{mg}$, had a further rootle through his notes and found he was already on it, a fact recorded in the A\&E admitting notes but never entered on his chart. A simple mistake was corrected and this man was allowed freedom from his demons. Psychiatry's die was, if not fully set, cast.

Ian Rowbotham, CT1 in Psychiatry, St Mary's Kettering, East Midlands Deanery 